\title{
Ärztinnen und Ärzte im eidgenössischen Parlament
}

Nachdem sich im Vorfeld der eidgenössischen Wahlen 2007 die meisten ärztlichen Kandidatinnen und Kandidaten für den National- und Ständerat mit Kurzporträts in der SÄZ vorgestellt hatten, möchten wir der Leserschaft nun zeigen, wer unseren Berufsstand ab der kommenden Wintersession in Bern vertritt. Die nachfolgende Übersicht könnte aufgrund der in verschiedenen Kantonen anstehenden zweiten Wahlgänge für den Ständerat noch leichte Veränderungen erfahren, über die wir gegebenenfalls informieren werden.

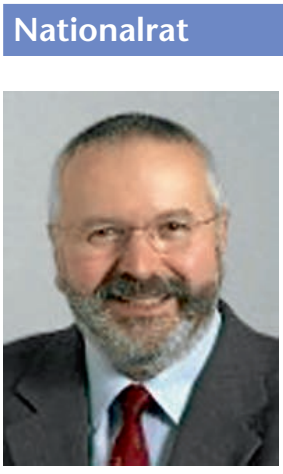

Dominique Baettig

1953, Jura, UDC (nouveau)

Médecin spécialiste en psychiatrie FMH

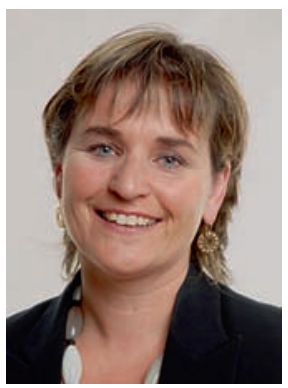

Marina Carobbio Guscetti

1966, Ticino, PS

Specialista in medicina generale FMH

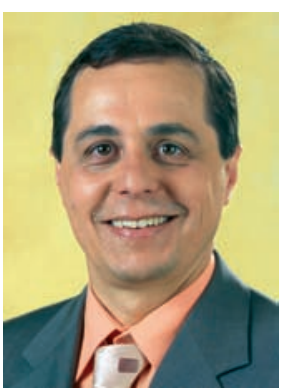

Ignazio Cassis

1961, Ticino, PLR

Specialista in prevenzione e salute pubblica FMH e specialista in medicina interna FMH

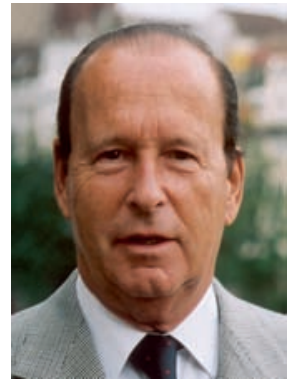

Jean Henri Dunant

1934, Basel-Stadt, SVP

Facharzt für Chirurgie FMH,

em. Privatdozent für Chirurgie

an der Universität Basel

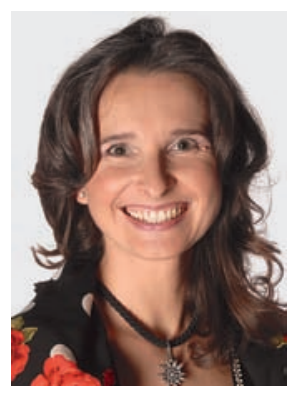

Yvette Estermann

1967, Luzern, SVP (neu)

Dr. med., Ärztin für klassische Homöopathie

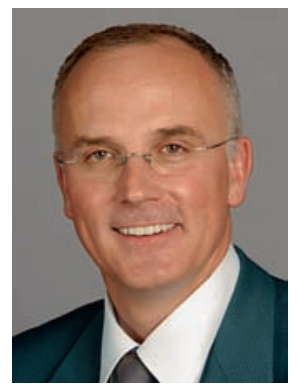

Charles Favre

1957, Vaud, PRD

Médecin généraliste

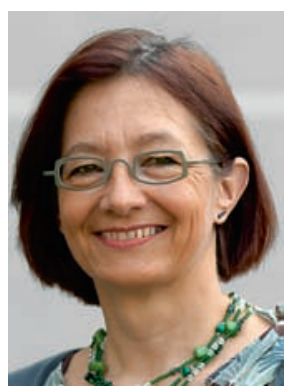

Yvonne Gilli

1957, St. Gallen, Grüne (neu)

Fachärztin für Allgemeinmedizin FMH, Homöopathie SVHA, TCM ASA

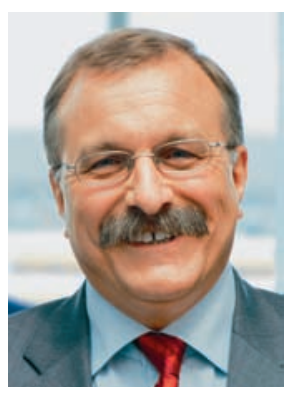

Jean-Charles Rielle

1952, Genève, PS (nouveau)

Médecin diplômé de santé publique

\section{Ständerat}

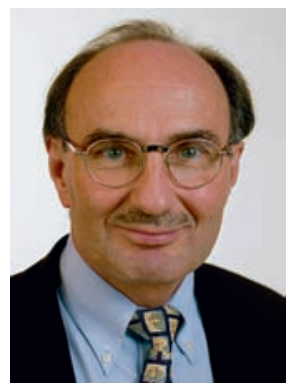

Felix Gutzwiller

1948, Zürich, FDP (neu)

Prof. Dr. med.,

Direktor ISPM der Universität Zürich 